\title{
Coding interaural time differences at low best frequencies in the barn owl
}

\author{
Catherine E. Carr ${ }^{\mathrm{a}, *}$, Christine Köppl ${ }^{\mathrm{b}}$ \\ a Department of Biology, University of Maryland, Biology-Psychology Building, Room 4227, College Park, MD 20742-4415, USA \\ ${ }^{\mathrm{b}}$ Lehrstuhl für Zoologie, Technische Universität München, Lichtenbergstrasse 4, 85747 Garching, Germany
}

\begin{abstract}
In birds and mammals, precisely timed spikes encode the timing of acoustic stimuli, and interaural acoustic disparities propagate to binaural processing centers. The Jeffress model proposes that these projections act as delay lines to innervate an array of coincidence detectors, every element of which has a different relative delay between its ipsilateral and contralateral excitatory inputs. Thus, interaural time difference (ITD) is encoded into the position of the coincidence detector whose delay lines best cancel out the acoustic ITD. Neurons of the avian nucleus laminaris and mammalian MSO phase-lock to both monaural and binaural stimuli but respond maximally when phase-locked spikes from each side arrive simultaneously, i.e. when the difference in the conduction delays compensates for the ITD. McAlpine et al. [Nat. Neurosci. 4 (2001) 396] identified an apparent difference between avian and mammalian ITD coding. In the barn owl, the maximum firing rate appears to encode ITD. This may not be the case for the guinea pig, where the steepest region of the function relating discharge rate to interaural time delay (ITD) is close to midline for all neurons, irrespective of best frequency (BF). These data suggest that low BF ITD sensitivity in the guinea pig is mediated by detection of a change in slope of the ITD function, and not by maximum rate. We review coding of low best frequency ITDs in barn owls and mammals and discuss whether there may be differences in the code used to signal ITD in mammals and birds.
\end{abstract}

(c) 2004 Elsevier Ltd. All rights reserved.

Keywords: Auditory; Bird; Brainstem; Evolution; Timing

\section{Introduction}

In the auditory system, accurate coding of temporal information has direct behavioral relevance for sound localization. In birds and mammals, precisely timed spikes encode the timing of acoustic stimuli, and interaural time differences (ITDs) propagate to binaural processing centers such as the avian nucleus laminaris and the mammalian medial superior olive $[20,47,130]$.

In birds, projections from the cochlear nucleus magnocellularis to the nucleus laminaris act as a delay lines $[19,82]$ and the projection from mammalian spherical bushy cells to the medial superior olive has been proposed to serve a similar role $[6,107]$. Delay line axons synapse on an array of coincidence detectors, every element of which has a different relative delay between

\footnotetext{
${ }^{*}$ Corresponding author. Tel.: +1-301-405-2085; fax: +1-301-3149358.

E-mail address: cc117@umail.umd.edu (C.E. Carr).
}

its ipsilateral and contralateral excitatory inputs. Thus, ITD is encoded into the position (a place code) of the coincidence detector whose delay lines best cancel out the acoustic ITD (for reviews, see [47,53]). The neurons of nucleus laminaris and MSO act as coincidence detectors, in that they phase-lock to both monaural and binaural stimuli and respond maximally when phaselocked spikes from each side arrive simultaneously, i.e. when the difference in the conduction delays compensates for the ITD $[20,36,82,86,87,128]$. In this theory, a network composed of delay lines and coincidence detectors explains how ITDs are computed [44].

The coincidence detectors of nucleus laminaris and MSO fire maximally at a particular ITD (and at intervals $2 \pi$ apart). Recordings from these neurons show multiple peaks at time lags corresponding to the ITD and integer multiples of the stimulus period (see [54]). In specific examples from dog [36], cat [128] and barn owl [20], this preferred ITD has been shown to be equal and opposite to the difference in neural delays between the responses to stimulation of either ear alone. Measures of 
this characteristic delay in cats and rabbits $[5,127]$ and barn owls [119] show a coincidence of peaks in the inferior colliculus, and in the nucleus laminaris $[20,87]$. It seems likely that barn owl and cat IPD coding neurons signal the best ITD or characteristic delay through a peak or rate code mechanism.

Recent studies in the guinea pig [71] have pointed out that there are major difficulties associated with using a peak code to signal ITD at low best frequencies. These difficulties are particularly acute when the animal has a small head and only a few hundred microseconds of available interaural time difference. McAlpine et al. [71] have shown that at frequencies below about $1 \mathrm{kHz}$, it is the slope of the ITD plot that tends to be centered around $0^{\circ}$ ITD, not the peak. Is there a fundamental difference between birds and mammals in the code used to signal ITD in low frequency sounds, or do both birds and mammals use the slope to determine location at low best frequencies, and switch to peak detection when the information content of the peak increases?

We will review the literature on ITD coding in birds and mammals and present a few recordings from low best frequency barn owl NL that suggest that low best frequency coincidence detector neurons in the owl also have the slope of the ITD function within the biological range of ITDs, and not the peak. Both sections will be used to support the hypothesis that birds and mammals use similar strategies for auditory coding, including "slope" coding at low best frequency ITDs, and "peak coding" for higher best frequencies. In the discussion we will identify similarities among the brainstem circuits that detect interaural time differences in birds and mammals, and argue that these are the result of parallel evolution (see review in [21]). Evidence for parallel evolution comes from the observation that tetrapod tympanic ears are not homologs, and may have evolved independently at least five times (modern representatives given in brackets) in synapsids (mammals), lepidosauromorph diapsids (snakes and lizards), archosauromorph diapsids (birds and crocodilians), probably turtles, and amphibians [23,69,70]. Wilcynzski [122] has argued that these peripheral changes would have different reorganizing effects upon the ancestral population of brainstem auditory neurons, leading to the parallel evolution of the central targets of the auditory nerve. Further developments in different ancestral groups, such as moveable ears and multiple ossicles in mammals, might have had additional reorganizing effects.

Parallel development is a plausible outcome of auditory system evolution, because animals with tympanic ears should experience similar constraints in detecting sounds [69]. When evidence supports the existence of similar algorithms in the auditory system of birds and mammals, we can argue that these have evolved because they are suited to extracting the stimulus variables rel- evant for auditory coding [20]. Neural codes for sound location have been the subject of inquiry from numerous groups working on barn owls [53,54,85], cats [64,129], rabbits [4,27,28], guinea pigs [71,102,105] and gerbils [9]. Detection of ITDs remains fertile ground for inquiry into the varieties of neural codes.

\section{Materials and methods}

The data presented here were made in the course of experiments on the barn owl's nucleus angularis (the region representing low frequencies in the nucleus laminaris is adjacent to the nucleus angularis) and the methods presented here may be found in detail in [59]. Results are reported from experiments on five barn owls (Tyto alba). Most animals were used in 2-3 separate experiments, spaced several days apart. Anaesthesia was induced by intramuscular injections of $10-14 \mathrm{mg} / \mathrm{kg}$ ketamine hydrochloride ("Ketavet" Phoenix, St. Joseph, MO) and 2-3 mg/kg xylazine ("xyla-ject", Phoenix), supplementary doses of ketamine and xylazine were administered according to individual needs (on average $\approx 7 \mathrm{mg} / \mathrm{kg} / \mathrm{h}$ ketamine and $1.5 \mathrm{mg} / \mathrm{kg} / \mathrm{h}$ xylazine).

\subsection{Surgery}

A metal headplate, as well as a short metal pin marking a standardized zero point, were permanently glued to the skull. Electrodes were placed into the brainstem stereotactically through the main part of the cerebellum. Owls were placed on a vibration-isolated table within a sound-attenuating chamber (IAC, New York) that was closed during all recordings. Commercial, Epoxylite coated tungsten electrodes (Frederick Haer Corporation, ME) were used. A grounded silver chloride pellet served as the reference. Electrode signals were amplified and filtered by a custom-built headstage and amplifier. The recording was then passed in parallel to an oscilloscope, a threshold discriminator (TuckerDavis Technologies, TDT; SD1) and an analog-to-digital converter (TDT DD1) connected to a personal computer via an optical interface (TDT OI). TTL pulses from the threshold discriminator were also registered by the personal computer via an additional timing module (TDT ET1), with a precision of $10 \mu \mathrm{s}$.

\subsection{Stimulus generation and calibration}

Acoustic stimuli were digitally generated by custom software ("Xdphys" written in Dr. M. Konishi's lab at Caltech) controlling a signal-processing board (TDT DSP2). After passing a digital-to-analog converter (TDT DD1) and an anti-aliasing filter (TDT FT6-2), the signals were variably attenuated (TDT PA4), impedance-matched (TDT HB4) and attenuated by an addi- 
tional fixed amount before being fed to miniature earphones. Two separate channels of signals could be generated, passing through separate channels of all associated hardware and driving two separate earphones. The earphones were housed in custom-built, calibrated, closed sound systems, inserted into the owl's left and right ear canal, respectively. Sound pressure levels were calibrated individually at the start of each experiment, using built-in miniature microphones.

\subsection{Stimulus paradigms and unit characterization}

While lowering the electrode, noise bursts $(50 \mathrm{~ms}$ duration, 5 bursts/s) were played to the ipsilateral ear as search stimuli. Once auditory responses were discernable, different frequencies and both ipsi- and contralateral stimuli were tested to judge the position of the electrode and whether the area was binaural. After isolating spikes, the characteristic frequency $(\mathrm{CF})$ was estimated audiovisually and the TTL trigger level was adjusted carefully. Phase locking quality was expressed as vector strength (VS, [36]), with values between 0 (homogeneous distribution of spikes across the stimulus period) and 1 (perfect synchronization with all spikes occurring at the same stimulus phase). In tests for phase locking, tone bursts (50 ms total duration, $5 \mathrm{~ms}$ rise-fall time, fixed starting phase, $200 \mathrm{~ms}$ cycle) at the estimated $\mathrm{CF}$ and a level at least $20 \mathrm{~dB}$ above threshold were presented between 5 and 100 times (five times when vector strength (VS) was calculated from the ITD data set, 100 when from a specific measure to determine PSTH). These parameters were chosen to estimate the maximal VS a unit could produce. Only statistically significant VS were accepted (Rayleigh test, $p<0.05$ ). Peri-stimulus-time histograms (PSTH) and interval histograms were also determined (Fig. 5). At one recording site, a small lesion was induced by passing pulsed, positive current of $2 \mu \mathrm{A}$ for $8 \mathrm{~min}$ through the electrode. After a survival time of 13 days, the owl was sacrificed by an anesthetic overdose and perfused transcardially with saline, followed by an aldehyde fixative. The brain was dissected out and cryoprotected by incubation in $30 \%$ buffered sucrose until it sank. Frozen sections were cut in the same (approximately transverse) plane as the electrodes had penetrated. Sections were mounted on gelatine-coated slides, stained with cresyl violet and coverslipped. All sections surrounding and including NL were examined at low magnification, scanning for damage or glial accumulation potentially associated with lesions.

\section{Results}

There is an inherent limitation to the accuracy of the processing of interaural phase disparities at low best frequencies [58]. The peak of a low best frequency ITD function is so broad that only a small change in rate can take place across the biological range of ITDs available to animals with small heads. Nevertheless, barn owls and other animals localize low frequency sounds well [49]. We present data on recordings from the low best frequency neurons in the barn owl nucleus laminaris that could support the hypothesis [71] that birds and mammals both use the change in rate or slope coding at low best frequencies.

\subsection{Behavioral data}

In 1979, Knudsen and Konishi [51] measured tonal sound localization accuracy for both azimuth and elevation of a sound source. Owls are reluctant to make head movements to frequencies below $3 \mathrm{kHz}$ and above $8 \mathrm{kHz}$. Knudsen and Konishi were, however, able to obtain azimuthal localization error measures of $11.9 \pm 11.8$ degrees for $1 \mathrm{kHz}$ tones (Fig. 1). Thus behavioral data show that barn owls are able to localize sound in azimuth at low best frequencies. It is clear they are much less accurate at localizing tones than noise, where they have an accuracy of less than 5 degrees [52] (see Fig. 1). Nevertheless, the Knudsen and Konishi data suggest that barn owls are able to use interaural phase differences to detect sound source location at 1 $\mathrm{kHz}$.

\subsection{Phase-locking below $2 \mathrm{kHz}$}

Like other birds and reptiles, the owl's auditory system encodes the phase of low best frequency sounds well. Köppl [57] has measured phase-locking in both the auditory nerve and the nucleus magnocellularis of the same individuals and found no difference in the lowfrequency range, up to about $1 \mathrm{kHz}$ (Fig. 2). Thus barn owls possess the temporal information needed to encode and detect interaural time differences. Barn owl auditory nerve fibers, in contrast to those of other species, are distinguished by being able to phase lock to frequencies up to about $9 \mathrm{kHz}[57,110]$. Their major peripheral specializations appear to be both high frequency phase locking and a massive overrepresentation of frequencies between 3 and $10 \mathrm{kHz}[56,60]$. In other regards, barn owl auditory nerve fiber responses are very similar to the typical patterns seen in other bird species [56,61], review in [34].

\subsection{Anatomy and cell types of the low frequency pathway in owls: delay lines at low best frequencies?}

Despite similar azimuthal accuracy at all frequencies, the low best frequency regions of the nucleus magnocellularis and the nucleus laminaris are not organized in exactly the same way as the regions that encode sound 

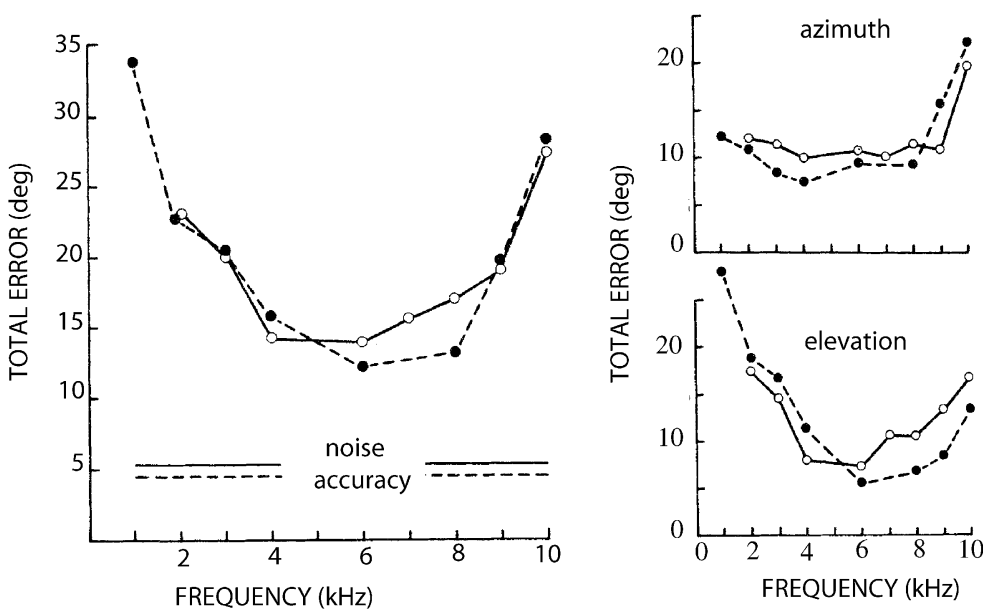

Fig. 1. Frequency dependence of sound localization. Head orientation error to tonal targets under open loop (solid line) and closed-loop (dashed line) conditions, plotted as a function of tone frequency. The owl's mean total errors are plotted on the left, the azimuthal and elevational components of these errors are plotted separately on the right (from [52], their Fig. 3). Axis units on right hand side graphs are the same as left.

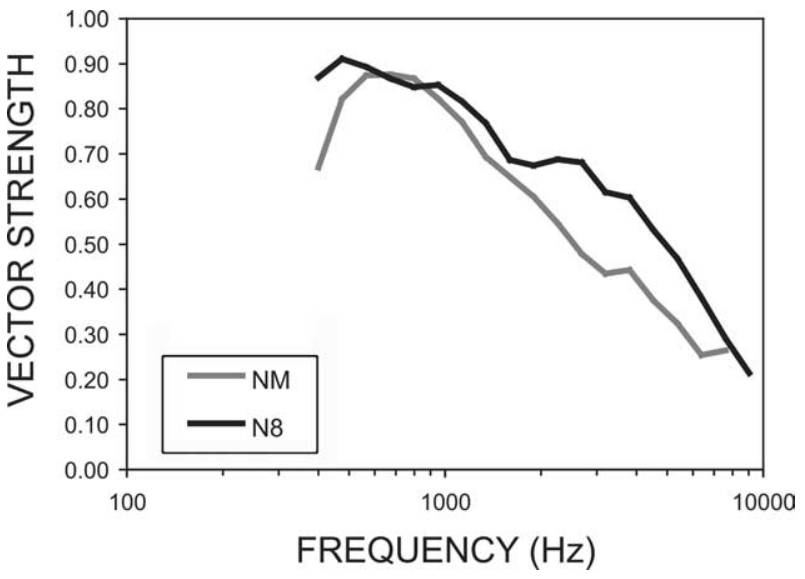

Fig. 2. Phase locking as a function of best frequency in the barn owl auditory system. The degree of phase locking quality is expressed as vector strength, which varies between 0 (homogeneous distribution of spikes across the stimulus period) and 1 (perfect synchronization with all spikes occurring at the same stimulus phase). The black line shows the median curve for auditory nerve fibers (after [57]). The grey line plots equivalent data from NM units (modified from Köppl, 1997c, her Fig. 4c, incorporating data from Carr and Konishi, 1990, their Fig. 5).

above about $1-2 \mathrm{kHz}$. First, low best frequency auditory nerve fibers do not form endbulbs, but rather bouton terminals, on the neurons of nucleus magnocellularis [55]. Second, their targets in the nucleus magnocellularis do not exhibit the large round cell bodies characteristic of nucleus magnocellularis principal neurons with best frequencies above about $2 \mathrm{kHz}$. There are two kinds of very low best frequency magnocellularis neuron, a small round cell, like the higher best frequency principal cell but smaller and with more dendrites, and a stellate cell with an oval cell body [58]. Third, the axons that project from nucleus magnocellularis to low best frequency nucleus laminaris are not as thick or straight as the magnocellular axons shown to act as delay lines in the higher best frequency regions $[18,58]$.

The organization of the low best frequency region of nucleus laminaris also differs from the regions that encode sound above about $1-2 \mathrm{kHz}$. The organization of the barn owl nucleus laminaris is best explained by comparison with homologous structures in basal land birds such as the chicken. In the chicken, nucleus laminaris is composed of a layer of bipolar neurons that receive tonotopically organized input from nucleus magnocellularis, with input from the ipsilateral nucleus magnocellularis onto their dorsal dendrites and input from the contralateral nucleus magnocellularis onto their ventral dendrites $[22,89,96]$. The axons from the contralateral nucleus magnocellularis form an elongated band of endings along the mediolateral length of the nucleus. These contralateral axons act as delay lines to form a map of ITDs along the mediolateral dimension of nucleus laminaris $[82,84,130,131]$. Delays are detected by coincidence detection in nucleus laminaris neurons $[82,84]$.

The organization of the barn owl nucleus laminaris differs from the basal land bird pattern. In regions with best frequencies above about $2 \mathrm{kHz}$, the cells are expanded from the monolayer structure typical of the chicken. They no longer form a flat sheet but a 1-mmthick neuropil with the neurons sparsely distributed throughout a plexus of myelinated fibers. Interaural time difference is mapped in the dorso-ventral direction in the barn owl nucleus laminaris, and not in the mediolateral direction (Fig. 3, [62,63,111]). The organization of the low best frequency region of barn owl nucleus laminaris is closer to the basal land bird pattern, except that the neurons are not neatly arranged in a cellular monolayer, with their dendrites polarized in the dorso-ventral dimension. Instead they are arranged more loosely, with their bitufted dendrites oriented in all 


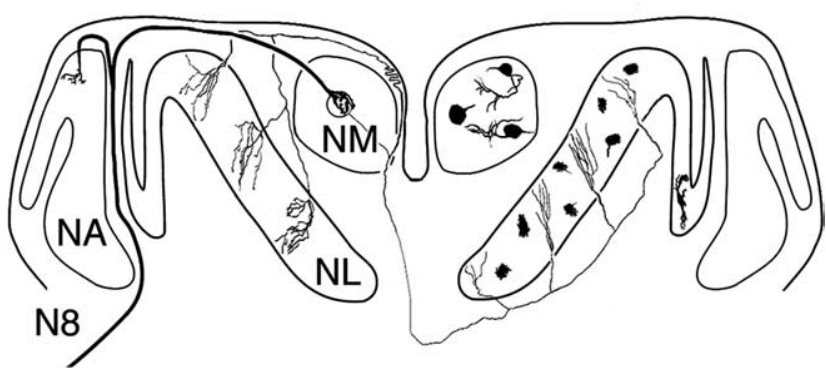

Fig. 3. Schematic transverse section through the brainstem of the barn owl. The medial branch of the auditory nerve (labeled N8) innervates nucleus magnocellularis (NM). Nucleus laminaris (NL) receives bilateral projections from NM. The nucleus magnocellularis axons act as delay lines to form a map of ITD in the dorsoventral dimension of NL. Nucleus laminaris cells act as coincidence detectors to encode ITD [20]. The low best frequency region is not organized in the same way. The nucleus laminaris neurons have longer dendrites, not oriented with respect to the borders of the nucleus.

directions [58]. There is also no clear evidence for delay lines in the projection from the nucleus magnocellularis [58]. These nucleus magnocellularis axons are thinner than those from the typical higher-frequency neurons, and branch repeatedly both outside and inside the nucleus laminaris, forming many en-passant and terminal bouton-like swellings within the caudolateral nucleus laminaris. The terminal arborizations always span the full thickness of the nucleus laminaris [58].

Since the arborizations of nucleus magnocellularis axons were not strictly oriented across the thickness of the caudolateral nucleus laminaris, a straight interdigitation of inputs from both sides, the basis of the delay lines in the owl's medial nucleus laminaris, does not appear to be present. In addition, the thickness of the caudolateral nucleus laminaris is only about half that of the medial nucleus laminaris and would thus seem insufficient to create a conductional delay in the same physiological range. An alternative dimension for the creation of delay lines would be along the isofrequency bands (as in the chicken and the cat), i.e. in the rostrocaudal dimension. Both of the low-frequency nucleus magnocellularis neurons whose ipsilateral axons were partly reconstructed, however, resembled the sequential branching patterns thought to be typical for contralateral arbors [58]. The possible absence of systematic delay lines in the low-frequency circuit is not in conflict with the presence of ITD sensitivity, where binaural inputs are all that is required. Interdigitating nucleus magnocellularis axons are only necessary to form a map of ITD, as shown for the $4-7.5 \mathrm{kHz}$ region of barn owl nucleus laminaris [20,111].

In summary, the most caudal low best frequency region of barn owl nucleus laminaris conforms to the basal land bird pattern to some extent. The nucleus laminaris neurons do not form either a monolayer or compact layer (Fig. 3, [58,114]). Instead the layer of bipolar neurons is disorganized, and the anatomical basis for delay lines is not clear. Thus, the anatomical organization of this region does not provide clear support for the existence of a low best frequency delay line network. The nucleus laminaris neurons appear to act as coincidence detectors (see below) but evidence for a map of ITD is presently lacking.

\subsection{Recordings from low CF nucleus laminaris neurons: coincidence detection below $2 \mathrm{kHz}$}

Selectivity to ITD was found in 10 binaural neurons tuned to characteristic frequencies between 200 and $2000 \mathrm{~Hz}$ (Table 1). The locations of these recordings were consistent with sites being in the low best frequency arm of nucleus laminaris: A lesion in case 101 was centered in the low best frequency arm of nucleus laminaris (Fig. 4), and in most of the other cases (owls 111, 113,712 ) recordings were subsequently made in the adjacent nucleus angularis (see [58]). Our aim in all cases

Table 1

Data for 10 NL neurons from 5 barn owls, showing cell number, stimulus frequency, vector strength at best ITD, maximum and minimum rates and the $\mathrm{min} / \mathrm{max}$ ratio (MOD)

\begin{tabular}{|c|c|c|c|c|c|c|c|c|}
\hline Unit & $\begin{array}{l}\text { Frequency } \\
(\mathrm{Hz})\end{array}$ & $\begin{array}{l}\text { VS at best } \\
\text { ITD }\end{array}$ & $\begin{array}{l}\text { ITD } \\
\text { CLOSEST TO } 0\end{array}$ & $\begin{array}{l}\text { Max response } \\
\text { (spikes/sec) }\end{array}$ & $\begin{array}{l}\text { Min response } \\
\text { (spikes/sec) }\end{array}$ & MOD & $\begin{array}{l}\text { Spont. rate } \\
\text { (spikes/sec) }\end{array}$ & Side \\
\hline 004.06.02.itd & 200 & 1.0 & & 196 & 4 & 0.98 & 3 & $\mathrm{R}$ \\
\hline 004.03.01.itd & 300 & 0.98 & & 24 & 0 & 1 & 3.8 & $\mathrm{R}$ \\
\hline 113.02.01.itd & 400 & 0.89 & 450 & 236 & 110 & 0.518 & 28 & $\mathrm{~L}$ \\
\hline 004.05.07.itd & 400 & 0.67 & & 240 & 0 & 1 & 23.6 & $\mathrm{R}$ \\
\hline $003.01 .12 . \mathrm{itd}$ & 400 & 0.96 & & 644 & 6 & 0.991 & 4.8 & $\mathrm{R}$ \\
\hline 003.02.03.itd & 400 & 0.78 & & 360 & 12 & 0.967 & 2 & $\mathrm{R}$ \\
\hline 004.02.01.itd & 500 & 0.75 & & 580 & 20 & 0.966 & 49.2 & $\mathrm{R}$ \\
\hline 101.02.09.itd & 1000 & 0.88 & 235 & 20 & 0 & 1 & 0.4 & $\mathrm{~L}$ \\
\hline 351.277.itd & 1025 & 0.78 & -337 & 490 & 20 & 0.96 & 18 & $\mathrm{R}$ \\
\hline 101.01.08.itd & 2000 & 0.63 & 168 & 82 & 0 & 1 & 1 & $\mathrm{~L}$ \\
\hline
\end{tabular}

Negative ITDs mean left ear leading, by convention. Note that best ITD was not reported for animals 004 and 003 where the contralateral earphone was not appropriately calibrated. The location of the recording is shown as $\mathrm{R}=$ right or $\mathrm{L}=$ left nucleus laminaris. Data from unit 351.277 have been published previously [20]. 


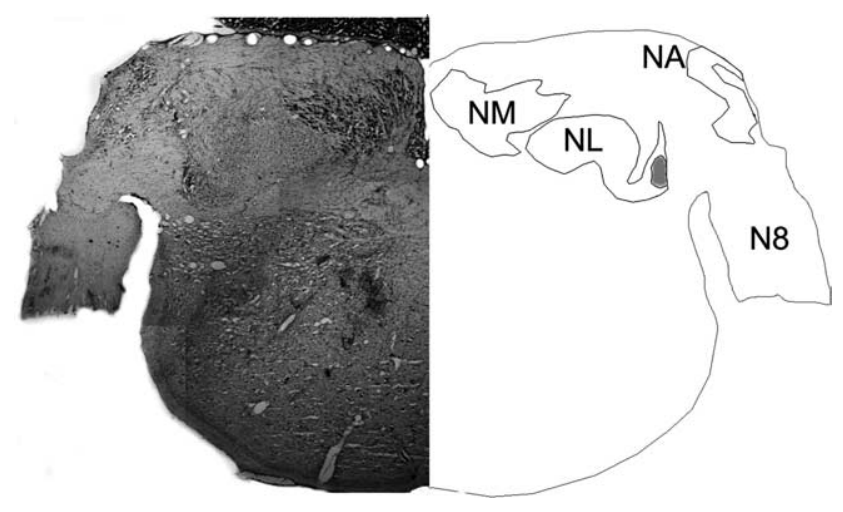

Fig. 4. Cross-section through the barn owl auditory brainstem at the level of the low best frequency region of nucleus laminaris shows a lesion in lateral nucleus laminaris. On the right hand side, a camera lucida drawing (reversed) of the same hemisection is shown, pointing out the lesion (grey fill) and the low best frequency region of NL. $\mathrm{NA}=$ cochlear nucleus angularis.

had been to record from the nucleus angularis, and our stereotaxic coordinates were selected to penetrate the lateral third of the brainstem.

The response of almost all nucleus laminaris neurons varied in a cyclic manner with the IPD of a sound stimulus, and the period of the IPD response function matched that of the stimulus tone. Low best frequency laminaris neurons phase-locked to the auditory stimu- lus, and were driven by both monaural and binaural stimuli. Evidence for coincidence detection at higher best frequencies comes from comparisons of period histograms that show phase-locked responses to stimulation of either the contralateral or ipsilateral ears [20]. These were measured for 2 units. Neuron 101.01 had a best ITD of $+168 \mu \mathrm{s}$, and a difference in mean phase of $+135 \mu$ s, a $33 \mu$ s difference between observed and expected ITD (Table 1). Unit 351.277 [20] had an estimated best ITD of $-337 \mu$ s, an observed difference in mean phase of $-373 \mu \mathrm{s}$, and a $36 \mu$ s difference between observed and expected ITD. The fairly close match between observed and expected best ITD suggests that a similar coincidence mechanism underlies the appearance of low best frequency IPD sensitivity as that in barn owl nucleus laminaris neurons of higher best frequency $[20,86,87]$.

The physiology of laminaris neurons with low best frequencies resembled higher best frequency nucleus laminaris neurons in other ways, with a primary-like discharge pattern, and generally low levels of spontaneous activity (Figs. 5 and 6, Table 1). Fig. 5 shows a typical low best frequency laminaris neuron stimulated with $500 \mathrm{~Hz}$ tones of varying interaural phase difference. This neuron's preferred interaural delay appeared to be about $+500 \mu$ s (or right ear leading by $500 \mu$ s). Panel 5A shows mean spike counts obtained by varying interaural
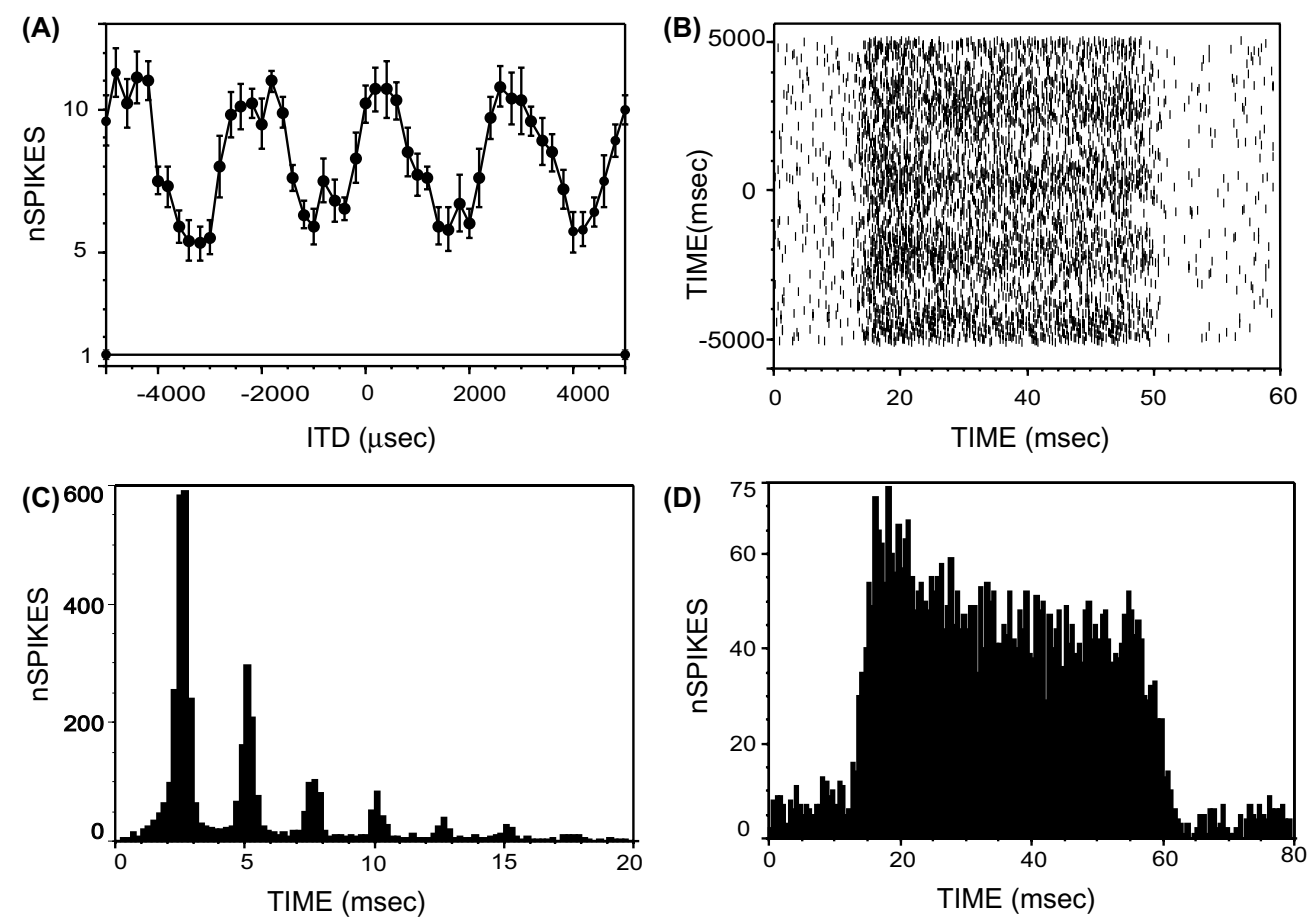

Fig. 5. Responses of NL neuron 113.02, stimulated at best frequency (400 Hz). (A) Interaural delay curve for NL neuron yielded ITD tuning with a peak to the right of 0 ITD. The spontaneous rate is indicated by the solid line along the baseline. The filled circles show mean spike counts $( \pm \mathrm{SD})$ obtained by varying interaural delay over a wide (non-biological) ranges of ITDs. Number of spikes shown for 50 ms stimulus presentation. (B) Raster plot of the data at BF, at $50 \mathrm{~dB}$ SPL and $30 \mathrm{~dB}$ above threshold, obtained for the stimulus set in (A). (C) Interval histogram for the same unit. (D) Peri-stimulus time histogram (PSTH) for the same unit. 

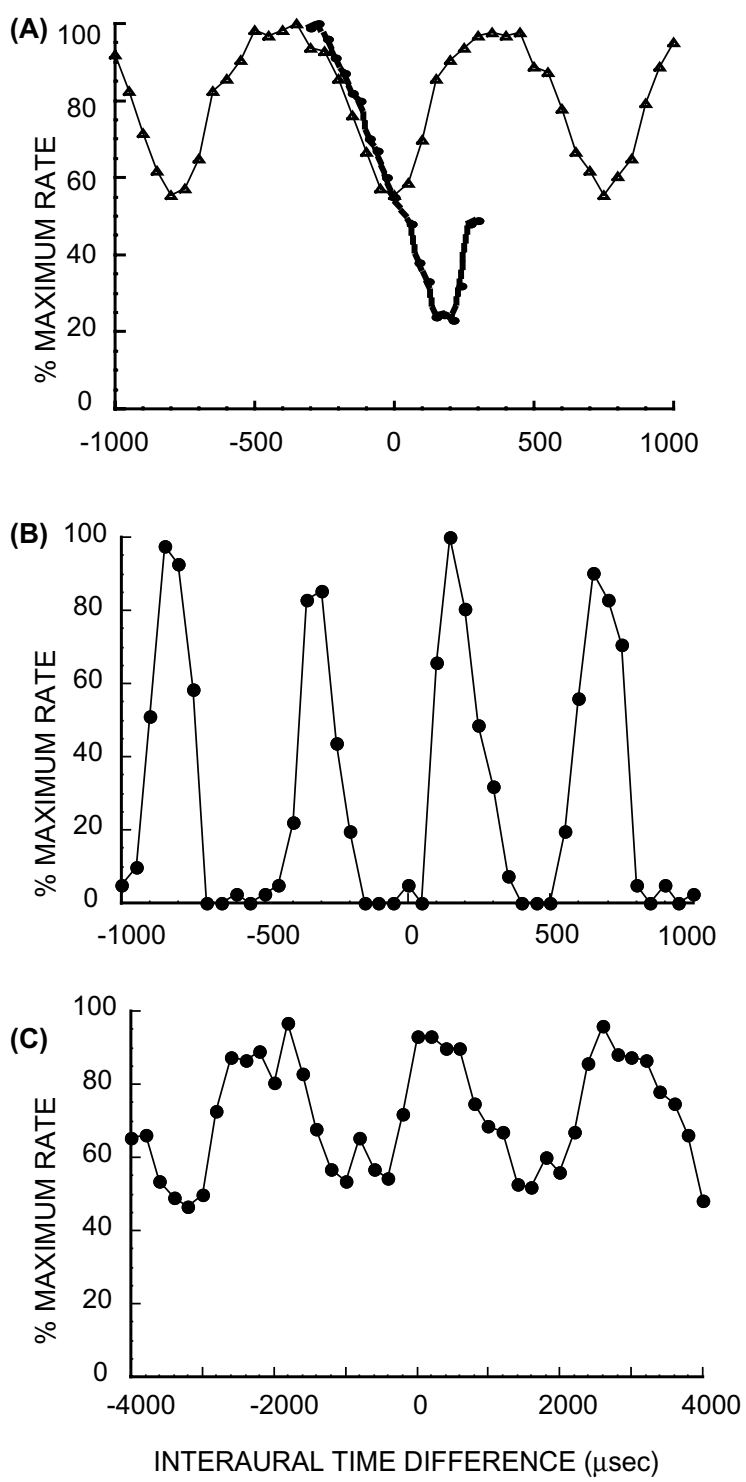

Fig. 6. Interaural delay curves plot the response of 4 low best frequency nucleus laminaris neurons against changing ITDs. Delay curves differ in maximum peak-to-trough height, and in rate. The numbers of spikes in each curve have been normalized to the maximum response. (A) Interaural delay curves for 2 NL neurons with best frequencies of $1025 \mathrm{~Hz}$ (351.277-see also Table 1, thick black line) and $1000 \mathrm{~Hz}$ (101.02, thin line). Both neurons had ITD tuning with peaks around and to the left of zero ITD. (B) Interaural delay curves for nucleus laminaris neuron 101.01, with a best frequency of $2000 \mathrm{~Hz}$. This neuron had an ITD peak to the right of zero, within the biological range available to the barn owl. Interaural delay curve for nucleus laminaris neuron 113.02, with a best frequency of $400 \mathrm{~Hz}$. This neuron had an ITD peak to the right of zero ITD.

delay over a wide (non-biological) range of ITDs. The raster plot of the data (Fig. 5B) shows a moderate level of spontaneous activity and the primary-like discharge pattern in response to the ITD stimulus is illustrated in panel 5D. The interspike-interval histogram for the same unit shows the phase-locked firing pattern (Fig. $5 \mathrm{C})$.
The major difference between neurons with best frequencies below $2 \mathrm{kHz}$ and those above is that none of the recorded neurons had peaks in their ITD functions at or near zero ITD (Fig. 6, Table 1). All peaks were further than $\pm 200 \mu$ s from zero. This time difference is significant because the ITDs available of the barn owl's head size are about $200 \mu$ s [72,73]. As was also the case for the guinea pig inferior colliculus, the representation of ITDs may vary with best frequency, although the data are presently too scarce to allow a definite conclusion. The neurons with the lowest best frequency $(400 \mathrm{~Hz}$, Table 1) had the longest interaural delays, while the neuron with the highest best frequency (near $2000 \mathrm{~Hz}$, Table 1) had the shortest interaural delay.

\section{Discussion and conclusions}

In 1997, Köppl and Carr pointed out inherent limitations to the accuracy of the processing of interaural phase disparities at low frequencies. Nevertheless, behavioral data showed that barn owls were able to localize sound at low best frequencies [51], Fig. 1. McAlpine et al. [71] have proposed a coding scheme to explain how animals with small heads can overcome the limitations of using peak coding at low best frequencies by detecting the change in slope of the ITD function instead of the peak. The difficulty with using the peak of a low best frequency ITD function is that it is so broad that there is only a small change in rate across the biological range of ITDs available to animals with small heads. The change in slope of the ITD function contains more information in this case $[5,105,118,128]$.

Although our sample is small, ITD coding in low best frequency regions of the barn owl is consistent with a slope code for ITD because the peaks of the ITD functions with best frequencies below $2 \mathrm{kHz}$ were at the edges of the biological range [13]. The appearance of a slope code for ITD at low best frequencies may be a parallel solution to the problem of low best frequency ITD coding. Studies of the gerbil have identified a distinct physiological mechanism, glycinergic inhibition, for shifting the ITD slope into the biological range [9]. It remains to be seen whether conduction delays, synaptic delays or a mechanism like stereausis (use of cochlear delays, explained further below) [8] applies in the barn owl.

Parallel evolution should be expected if there are computational advantages to a particular solution [21,59]. Selective pressure to encode higher frequency sounds may have driven the appearance of similar features of the auditory systems of archosaurs and mammals. We will review these similar features of brainstem auditory systems, and then discuss sensitivity to interaural time differences at low best frequencies. 


\subsection{Review of temporal coding in birds and mammals}

Accurate and precise processing of the auditory stimulus is required for sound localization. Auditory nerve fibers encode temporal information by phase locking to the waveform of the acoustic stimulus, and this temporal information is preserved in projections to the primary auditory nuclei. There are several shared features of temporal coding circuits in birds and mammals. These include accurate phase locking in the auditory nerve, presynaptic specializations to make neurotransmitter release both precise and modifiable, postsynaptic specializations, including specific glutamate receptors, potassium conductances and characteristic neuronal morphology (for reviews see $[30,79]$ ).

\subsubsection{Presynaptic specializations for encoding temporal information}

In the bird, auditory nerve afferents divide into two with one branch to the nucleus angularis, and the other branch to the nucleus magnocellularis [17,113]. In mammals, similar cell types receiving auditory nerve input are contained in a single nucleus, the ventral cochlear nucleus (see [98]). The termination of the auditory nerve onto the cell bodies of avian magnocellularis neurons and mammalian bushy cells takes the form of a specialized calyceal or endbulb terminal while avian NA neurons and mammalian stellate cells are contacted through bouton-like synapses $[10,17,26,45$, 97]. The endbulb terminals envelop the postsynaptic cell body and are characterized by numerous release sites [75,101]. Thus the endbulb injects synaptic currents into the cell body, not dendrites. Furthermore, the invasion of the presynaptic action potential into the calyx leads to the synchronous release of quanta at many endbulb release sites, giving this synapse a high safety factor of transmission [43]. Endbulbs therefore form a secure and effective connection for the precise relay of the phaselocked discharges of the auditory nerve fibers to their postsynaptic targets.

Phase-locking abilities are correlated with the presence of endbulb terminals because phase locking is preserved in the neurons of the nucleus magnocellularis, and lost at higher frequencies in the non-endbulb auditory nerve projection to the NA [57,59]. In the cat, there is a slight improvement in phase-locking between the nerve and the bushy cells of the cochlear nucleus for frequencies below about $1 \mathrm{kHz}$, due to monaural coincidence of auditory nerve fibers [16,46,95]. Endbulb terminals do not appear to be needed for transmission of phase-locked spikes at low frequencies. The very low best frequency cells of the nucleus magnocellularis receive bouton terminals from the auditory nerve [55] and phase-lock to frequencies below $\sim 1 \mathrm{kHz}$ [57]. The task of encoding temporal information precisely becomes more difficult with increasing frequency. This is because the absolute temporal precision required for phaselocking to high frequencies is greater than that needed for low frequencies, i.e., the same temporal jitter of spikes translates to greater variation in terms of phase for high frequencies [41,83]. Vector strength of phase locking decreases for frequencies above $1-2 \mathrm{kHz}$ (Fig. 3). Temporal dispersion, however, also decreases with frequency, indicating enhanced temporal synchrony as frequency increases.

Endbulb terminals may have emerged as an adaptation for accurate transmission of phase information for frequencies above $1000 \mathrm{~Hz}$, perhaps associated with the evolution of higher-frequency hearing in land vertebrates $[21,69]$. Large somatic terminals have been found in all amniote groups examined. Both somatic terminals and smaller boutons are found in nucleus magnocellularis of the red-eared turtle and the alligator lizard $[12,112]$. In crocodilian nucleus magnocellularis, the rostral high best frequency magnocellular neurons receive endbulb-like projections, while lower best frequency magnocellular neurons receive bouton terminals [109]. Thus it is possible that a large somatic terminal may have been present in the amniote common ancestor, and have developed in parallel in three major lines of the descendents of the stem reptiles (e.g., mammals, birdscrocodiles, and lizards-snakes) to mediate accurate transmission of temporal information at higher sound frequencies.

\subsubsection{Postsynaptic specializations for encoding temporal information}

Auditory neurons in birds and mammals possess a number of morphological and physiological specializations that make them well suited to preserve the temporal firing pattern of auditory nerve inputs. In addition to endbulb terminals, large cell bodies and reduced dendritic arbors serve to keep the cells electrically compact. Time coding neurons also possess a particular combination of synaptic and intrinsic membrane properties, including fast AMPA type glutamate receptors and specific $\mathrm{K}^{+}$conductances. These features lead to a single or few well timed spikes in response to a depolarizing stimulus (for reviews see $[22,79,116,117]$ ). A similar suite of physiological and morphological features also characterize the neurons of the medial nucleus of the trapezoid body and the type II neurons of the ventral nucleus of the lateral lemniscus, both of which receive endbulb synapses $[11,124,125]$.

Activation of AMPA receptors at endbulb synapses generates large brief synaptic currents $[43,88,132,133]$. EPSCs recorded from chick nucleus magnocellularis neurons decay with an estimated exponential time constant less than $0.1 \mathrm{~ms}$ [132]. The brevity of these currents depends not only on the time course of release but also on the specific properties of the postsynaptic AMPA receptors. AMPA receptors in time coding auditory 
neurons have fast kinetics and rapid desensitization rates, leading to very short EPSCs [30-32,88]. Although brief EPSCs underlie the rapid synaptic potential changes seen in time coding neurons, the intrinsic electrical properties of these neurons also shape the synaptic response as well as the temporal firing pattern. Voltage sensitive $\mathrm{K}^{+}$conductances determine the response properties of auditory neurons, and each cell type exhibits a distinct complement of outward $\mathrm{K}^{+}$currents $[3,67,77,123]$. At least two $\mathrm{K}^{+}$conductances underlie phase locked responses in auditory neurons: a low and a high threshold conductance $[11,67,90,91,120]$.

The low threshold conductance activates near rest to produce a short active time constant such that the effects of excitation are brief and do not summate in time [123] (see [78] for review). The high threshold conductance is characterized by an activation threshold around $-20 \mathrm{mV}$ and fast kinetics $[11,90,121]$. These features of the high threshold conductance result in rapid action potential repolarization and brief action potentials. This has the effect of minimizing $\mathrm{Na}^{+}$channel inactivation, allowing cells to reach firing threshold sooner and facilitating high frequency firing. Elimination of the Kv3.1 gene in mice results in the loss of a high-threshold component of potassium current and failure of the neurons to follow high-frequency stimulation $[65,120]$. Brief action potentials also reduce the amount of neurotransmitter released [99]. Coincidence detection models suggest that an increase in the width of the input EPSC could impair ITD coding [104].

\subsubsection{Temporal precision in responses of the cochlear nuclei and nucleus laminaris}

Not all temporal coding neurons are equal. Not only do the demands of temporal coding increase with increasing best frequency [41,58,83], but neurons encode different features of the temporal code. A good example may be found in comparisons of octopus cells and spherical bushy cells. They share many biophysical features but code different aspects of the stimulus.

Octopus cells in the posteroventral cochlear nucleus of mammals are biophysically specialized to detect coincident firing in the population of auditory nerve fibers that provide their synaptic input and to convey its occurrence with temporal precision [80]. These neurons require the summation of many synaptic inputs within a period of $1 \mathrm{~ms}$ to fire and thus detect coincident firing among their inputs [37]. In requiring the summation of many small inputs to produce a brief but robust synaptic response, the temporal jitter in the timing of individual auditory nerve inputs is lost in the firing of octopus cells. Instead, octopus cells convey the timing of broadband transients or periodicity with little jitter in vivo $[35,80,93,94]$. The precision in the timing of these action potentials depends on activation of voltage-dependent conductances that endow octopus cells with low input resistance and prevent repetitive firing in response to depolarization [2].

Bushy and medial nucleus of the trapezoid body cells share similar brief active constants and potassium conductances with octopus cells [67,68,76,81], but instead encode the phase of the auditory stimulus $[15,46,83]$. Bushy and trapezoid body neurons do not sum many synaptic inputs, as octopus cells do. Instead they receive a few endbulb synapses with large numbers of functional synaptic release sites per axon terminal. In spherical bushy cells, and MNTB and NM neurons, a single stimulus releases 100-200 transmitter quanta from each axon terminal $[42,133]$. This generates a very large excitatory postsynaptic current that brings the neuron to threshold rapidly and reliably, despite short-term depression [117]. Thus this large excitatory postsynaptic current mediates accurate transmission of phase locked information.

\subsection{Sensitivity to interaural time differences}

In birds and mammals, precisely timed spikes encode the timing of acoustic stimuli, and interaural acoustic disparities propagate to binaural processing centers such as the avian nucleus laminaris and the mammalian medial superior olive $[20,47,130]$. Detection of ITD has been understood on the basis of the Jeffress model [44] in which an array of coincidence detectors receive input from ipsilateral and contralateral excitatory inputs that act as delay lines. We will critically review the evidence for this model in the light of recent developments. We also note that birds and mammals use interaural level differences for sound localization. Use of interaural level differences has been recently been reviewed in mammals [115], and barn owls [54].

\subsubsection{Delay line-coincidence detection circuits in birds}

In chickens and owls, ITD is encoded into the position (a place code) of the coincidence detector whose delay lines best cancels out the acoustic ITD [20,53, $54,87]$. Neurons of nucleus laminaris act as coincidence detectors and respond maximally when phase-locked spikes from each side arrive simultaneously, i.e. when the difference in the conduction delays compensates for the ITD $[20,29,48,82,86,87]$. The detection of a range of ITDs is achieved through systematically delaying the arrival of spikes from one side, such that the neurons detect coincidence when the introduced delay is compensated by earlier arrival of the sound at the respective ear due to displacement of the sound source towards that ear. The anatomical basis for these delay lines is seen in the bilateral, tonotopic projection of the nucleus magnocellularis to the nucleus laminaris. In the chicken, each nucleus magnocellularis axon innervates the ipsilateral nucleus laminaris by dividing into several collaterals of approximately equal length that terminate at 
different points along the isofrequency band, predominantly in the dorsal neuropil of the nucleus laminaris's monolayer of multipolar neurons. On the contralateral side, the axon runs along the isofrequency band, successively giving off collaterals that terminate predominantly in the ventral neuropil [130]. It has been shown in chicken brain slice preparations, that, as expected from this innervation pattern, action potentials from the ipsilateral side arrive almost simultaneously at all innervated nucleus laminaris neurons, whereas action potentials from the contralateral side are increasingly delayed from caudolateral to rostromedial along the isofrequency band [82]. Thus a potential place map of ITD is formed along each isofrequency band. The range of this map in vivo has been estimated to be about 180 $\mu$ [ [82].

In the large medial, high-frequency region of the barn owl's nucleus laminaris, neurons are evenly and widely spaced, forming a thick nucleus where there is only a thin monolayer sheet in the chicken [63,114]. This additional dimension is used to create delay lines in the dorsoventral direction. While the basic projection pattern of nucleus magnocellularis neurons is similar to that in the chicken, once they have reached the nucleus laminaris, the axon collaterals traverse the nucleus in its full thickness in the owl. Collaterals from the ipsi- and contralateral nucleus magnocellularis, entering the nucleus laminaris from its dorsal and ventral border, respectively, interdigitate across its thickness and form multiple delay lines along each isofrequency band $[19,20]$. Recordings in the barn owl's nucleus laminaris have shown that this innervation pattern generates multiple maps of the same ITD, each covering 150-200 $\mu$ s $[19,20,87,111]$.

\subsubsection{Coincidence detectors in birds and mammals}

Despite the differences in organization of nucleus laminaris in owls and chickens, delay lines and coincidence detectors underlie ITD sensitivity in both species $[29,48,87,111]$. Very similar principles apply to the coincidence detector neurons of the mammalian superior olive $[36,128]$, but there is only anatomical evidence for delay lines in mammals, and the existence of a map of interaural time differences is still in question. We will therefore discuss coincidence detection and delays separately.

Coincidence detectors in mammals, birds and crocodilians share a common morphological organization [21]. Almost all are bitufted neurons with inputs from each ear segregated on the dendrites. Modeling studies suggest that this dendritic organization improves coincidence detection, although this improvement decreases with increasing best frequency [1,104]. These studies also show that coincidence detection does not seem to require prominent specializations at frequencies below 1 $\mathrm{kHz}$ [40]. A single compartment model endowed with
Hodkin-Huxley channels and appropriate phase-locked inputs acts as a good coincidence detector $[24,40]$.

Avian and mammalian coincidence detectors share physiological features with nucleus magnocellularis neurons and mammalian bushy and octopus cells. Coincidence detectors exhibit low threshold $\mathrm{K}^{+}$conductances that lead to a single or few well-timed spikes in response to a depolarizing stimulus in vitro $[92,106]$. These conductances act to decrease the effective membrane time constant i.e. the average membrane time constant for a cell receiving and processing in vivo rates of EPSPs, which will be much shorter than the passive membrane time constant $[33,66]$. Modeling studies suggest that these fast conductances may improve coincidence detection by keeping the firing rate near zero when the inputs are completely out of phase but allowing non-zero firing rate when the inputs are monaural [1].

Coincidence detectors in birds and mammals display similar conductances and bipolar morphologies, but they are not identical. The most substantial difference is in type and function of inhibitory inputs (recently reviewed in [38]). In mammals the MSO receives welltimed inhibitory input from the medial and lateral nucleus of the trapezoid body [14,39]. The glycinergic inhibition from the ipsilateral medial nucleus of the trapezoid body appears responsible for tuning the steep slope of ITD functions to the physiologically relevant range by suppressing the response to ITDs at which the ipsilateral stimulus is leading [9]. These results support the model in which the slope of the ITD function is used to encode sound location [71]. In birds, inhibitory inputs to nucleus laminaris are GABAergic, less temporally precise and appear to decrease excitability through a gain control mechanism that provides protection from changes in sound level $[29,74,86,126]$. Short-term synaptic plasticity may also contribute to coincidence detection [25]. Coincidence detection depends on the temporal coincidence, and synaptic depression provides an adaptive mechanism for preserving ITDs despite changes in sound level.

\subsubsection{Stereausis and delay lines}

The role of delay lines in creating maps of ITD, and the existence of such maps, has been called into question in the gerbil and guinea pig, and by extension in other mammals $[9,71]$. Coincidence detectors respond best to simultaneous input, but there may be several mechanisms that can produce simultaneous inputs in the face of ITDs. These include axonal or conduction delays, synaptic delays such as inhibition, and cochlear delays or stereausis.

Conduction delays account for ITD sensitivity in high best frequencies in the barn owl [19], while synaptic delays contribute to ITD sensitivity in the gerbil, where precisely timed glycinergic inhibition accounts for some 
portion of the delay in the medial superior olivary neurons in the gerbil [9]. It appears that in the gerbil inhibition acts to shift the peak response away from zero ITD so as to position the steepest slope of the ITD curve within the biological range of ITDs.

Cochlear delays, or the differences in wave propagation along the cochlea could provide the delays necessary for coincidence detection, if the coincidence detectors receive input from fibers innervating different loci on the left and right basilar membranes [103]. This is because the propagation time of the traveling wave along the basilar membrane causes high best frequency sites near the oval window to respond first and regions further apically to respond at later times. According to the stereausis theory, the selectivity of a coincidence detector for ITD is determined by the temporal disparity between the left and right cochlear loci from which it receives inputs. In this model, coincidence detectors that receive inputs from left and right auditory neurons tuned to the same frequency would be selective for an ITD of 0 , because their propagation delays are the same for the two sides (see discussion in [87]).

In barn owls, evidence is not consistent with the use of cochlear delays for ITD coding. Pena et al. [87] found that monaural frequency-tuning curves of nucleus laminaris neurons showed small interaural differences in frequency tuning. In addition, their preferred ITDs were not correlated with the interaural frequency mismatches. Instead, the preferred ITD of the neuron agreed with that predicted from the distribution of axonal delays [87]. Thus, neural delays are sufficient to explain the detection of ITDs by the barn owl at high best frequencies. The stereausis hypothesis may still apply to the mammalian medial superior olive because evidence for bushy cell projections to the neurons of the medial superior olive acting as delay lines is only anatomical $[6,108]$. Thus it is not known whether conduction delays from the cochlear nucleus are sufficient to account for best ITD sensitivity. Stereausis may also account for some portion of delay. Bonham and Lewis have pointed out that frequency differences may augment or diminish the effective difference in ipsilateral and contralateral axonal time delays from the periphery to the binaural comparison neuron. For example, frequency mismatches of 0.2 octaves or less for binaural neurons with characteristic frequencies of $250-2.5 \mathrm{kHz}$ may increase or decrease the effective time delay difference by as much as $400 \mu \mathrm{s}$ [8].

\subsubsection{Encoding ITDs at low best frequencies in birds and mammals \\ Most birds and mammals have small heads and thus a small range of ITDs. Both theory and known physi- ology suggest that frequencies below about $1 \mathrm{kHz}$ are unable to provide the temporal resolution that would be needed for precise localization based on a Jeffress-like}

map of ITD. Behavioral experiments have shown that the localization accuracy of owls along the azimuth does not deteriorate substantially using frequencies as low as $1 \mathrm{kHz}$, but there are no data for frequencies below that [52], Fig. 1). In a small song bird, the great tit, however, a marked decrease in azimuthal localization accuracy was observed for pure tones below $1 \mathrm{kHz}$ [50].

Mammals with small heads and sensitivity to low best frequencies may have evolved a solution to the problem of localizing low best frequencies. In the guinea pig, it has been suggested that there are only two broadly tuned channels in the inferior colliculus that represent ITD information, one located in the left inferior colliculus and the other in the right [71]. The peak responses of the neurons forming these channels are outside the physiological hearing range, while the highest variation of the responses with ITD (the maximal slope of the ITD curve) lies around zero ITD. Brand [9] suggested a "slope-code" model may explain sound localization with such broadly tuned channels. Although our small sample of barn owl nucleus laminaris neurons with best frequencies below $2 \mathrm{kHz}$ all had best ITDs outside the physiological range, consistent with using the slope to encode ITD, recording from the barn owl inferior colliculus do not support the hypothesis that owls have two broadly tuned channels in the inferior colliculus. In the barn owl central nucleus of the inferior colliculus, low best frequency ITD-sensitive neurons generally have response peaks distributed throughout the physiological ITD range [118]. Similarly recordings from optic tectum neurons show that best ITDs are usually well within the natural range [100].

\section{Acknowledgements}

We are grateful for Dr. M. Konishi's kind gift of the xdphys software, and for technical help from C. Malek, Dr. B. Arthur and Dr. J. Pena. Supported by NIDCD 000436 to CEC, and by a Heisenberg fellowship to CK.

\section{References}

[1] H. Agmon-Snir, C.E. Carr, J. Rinzel, The role of dendrites in auditory coincidence detection, Nature 393 (1998) 268-272.

[2] R. Bal, D. Oertel, Hyperpolarization-activated, mixed-cation current $(I(h))$ in octopus cells of the mammalian cochlear nucleus, J. Neurophysiol. 84 (2000) 806-817.

[3] R. Bal, D. Oertel, Potassium currents in octopus cells of the mammalian cochlear nucleus, J. Neurophysiol. 86 (2001) 22992311.

[4] R. Batra, S. Kuwada, D.C. Fitzpatrick, Sensitivity to interaural temporal disparities of low- and high-frequency neurons in the superior olivary complex. I. Heterogeneity of responses, J. Neurophysiol. 78 (1997) 1222-1236.

[5] R. Batra, S. Kuwada, D.C. Fitzpatrick, Sensitivity to interaural temporal disparities of low- and high-frequency neurons in the 
superior olivary complex. II. Coincidence detection, J. Neurophysiol. 78 (1997) 1237-1247.

[6] G.E. Beckius, R. Batra, D.L. Oliver, Axons from anteroventral cochlear nucleus that terminate in medial superior olive of cat: observations related to delay lines, J. Neurosci. 19 (1999) 31463161.

[8] B.H. Bonham, E.R. Lewis, Localization by interaural time difference (ITD): effects of interaural frequency mismatch, J. Acoust. Soc. Am. 106 (1999) 281-290.

[9] A. Brand, O. Behrend, T. Marquardt, D. McAlpine, B. Grothe, Precise inhibition is essential for microsecond interaural time difference coding, Nature 417 (2002) 543-547.

[10] J.R. Brawer, D.K. Morest, Relations between auditory nerve endings and cell types in the cat's anteroventral cochlear nucleus seen with the Golgi method and Nomarski optics, J. Comp. Neurol. 160 (1975) 491-506.

[11] H.M. Brew, I.D. Forsythe, Two voltage-dependent $\mathrm{K}^{+}$conductances with complementary functions in postsynaptic integration at a central auditory synapse, J. Neurosci. 15 (1995) 8011-8022.

[12] R.H. Browner, D.M. Pierz, Endbulbs of Held in a cochlear nucleus, nucleus magnocellularis in the red-eared turtle, Chrysemys scripta elegans, Soc. Neurosci. Abstr. 12 (1986) 1265.

[13] M.B. Calford, R.W. Piddington, Avian interaural canal enhances interaural delay, J. Comp. Physiol. 162 (1988) 503-510.

[14] N.B. Cant, R.L. Hyson, Projection form the lateral nucleus of the trapezoid body to the medial superior olivary nucleus in the gerbil, Hearing Res. 58 (1992) 26-34.

[15] L.H. Carney, Sensitivities of cells in anteroventral cochlear nucleus of cat to spatiotemporal discharge patterns across primary afferents, J. Neurophysiol. 64 (1990) 437-456.

[16] L.H. Carney, A model for the responses of low-frequency auditory-nerve fibers in cat, J. Acoust. Soc. Am. 93 (1993) 401417.

[17] C.E. Carr, R.E. Boudreau, The central projections of auditory nerve fibers in the barn owl, J. Comp. Neurol. 313 (1991).

[18] C.E. Carr, R.E. Boudreau, Organization of the nucleus magnocellularis and the nucleus laminaris in the barn owl: encoding and measuring interaural time differences, J. Comp. Neurol. 334 (1993) 337-355.

[19] C.E. Carr, M. Konishi, Axonal delay lines for time measurement in the owl's brainstem, Proc. Natl. Acad. Sci. USA 85 (1988) $8311-8315$

[20] C.E. Carr, M. Konishi, A circuit for detection of interaural time differences in the brainstem of the barn owl, J. Neurosci. 10 (1990) 3227-3246.

[21] C.E. Carr, D. Soares, Evolutionary convergence and shared computational principles in the auditory system, Brain Behav. Evol. 59 (2002) 294-311.

[22] C.E. Carr, D. Soares, S. Parameshwaran, T. Perney, Evolution and development of time coding systems, Curr. Opin. Neurobiol. 11 (2001) 727-733.

[23] J.A. Clack, The evolution of tetrapod ears and the fossil record, Brain Behav. Evolut. 50 (1997) 198-212.

[24] H.S. Colburn, Y. Han, C.P. Culotta, Coincidence model of MSO responses, Hearing Res. 49 (1990) 335-355.

[25] D.L. Cook, P.C. Schwindt, L.A. Grande, W.J. Spain, Synaptic depression in the localization of sound, Nature 421 (2003) 66-70.

[26] D.M. Fekete, E.M. Rouiller, M.C. Liberman, D.K. Ryugo, The central projections of intracellularly labeled auditory nerve fibers in cats, J. Comp. Neurol. 229 (1984) 432-450.

[27] D.C. Fitzpatrick, R. Batra, T.R. Stanford, S. Kuwada, A neuronal population code for sound localization, Nature 388 (1997) 871-874.

[28] D.C. Fitzpatrick, S. Kuwada, R. Batra, Transformations in processing interaural time differences between the superior olivary complex and inferior colliculus: beyond the Jeffress model, Hearing Res. 168 (2002) 79-89.
[29] K. Funabiki, K. Koyano, H. Ohmori, The role of GABAergic inputs for coincidence detection in the neurones of nucleus laminaris of the chick, J. Physiol. 508 (1998) 851-869.

[30] S.M. Gardner, L.O. Trussell, D. Oertel, Time course and permeation of synaptic AMPA receptors in cochlear nuclear neurons correlate with input, J. Neurosci. 19 (1999) 87218729.

[31] S.M. Gardner, L.O. Trussell, D. Oertel, Correlation of AMPA receptor subunit composition with synaptic input in the mammalian cochlear nuclei, J. Neurosci. 21 (2001) 7428-7437.

[32] J.R.P. Geiger, T. Melcher, D.-S. Koh, B. Sakmann, P.H. Seeburg, P. Jonas, H. Monyer, Relative abundance of subunit mRNAs determines Gating and $\mathrm{Ca}^{2+}$ permeability of AMPA receptors in principal neurons and interneurons of rat CNS, Neuron 15 (1995) 193-204.

[33] W. Gerstner, R. Kempter, J.L. van Hemmen, H. Wagner, A neuronal learning rule for sub-millisecond temporal coding, Nature 383 (1996) 76-81.

[34] O. Gleich, G.A. Manley, SHAR, in: R.J. Dooling, A.N. Popper, R.R. Fay (Eds.), Comparative Hearing: Birds and Reptiles, vol. 13, Springer, New York, 2000.

[35] D.A. Godfrey, N.Y. Kiang, B.E. Norris, Single unit activity in the posteroventral cochlear nucleus of the cat, J. Comp. Neurol. 162 (1975) 247-268.

[36] J.M. Goldberg, P.B. Brown, Response of binaural neurons of dog superior olivary complex to dichotic tonal stimuli: some physiological mechanisms of sound localization, J. Neurophysiol. 32 (1969) 613-636.

[37] N.L. Golding, D. Robertson, D. Oertel, Recordings from slices indicate that octopus cells of the cochlear nucleus detect coincident firing of auditory nerve fibers with temporal precision, J. Neurosci. 15 (1995) 3138-3153.

[38] B. Grothe, New roles for synaptic inhibition in sound localization, Nat. Rev. Neurosci. 4 (2003) 540-550.

[39] B. Grothe, D.H. Sanes, Synaptic inhibition influences the temporal coding properties of medial superior olivary neurons: an in vitro study, J. Neurosci. 14 (1994) 1701-1709.

[40] Y. Han, H.S. Colburn, Point-neuron model for binaural interaction in MSO, Hearing Res. 68 (1993) 115-130.

[41] K.G. Hill, G. Stange, J. Mo, Temporal synchronization in the primary auditory response in the pigeon, Hearing Res. 39 (1989) $63-74$.

[42] J.S. Isaacson, B. Walmsley, Counting quanta: direct measurements of transmitter release at a central synapse, Neuron 15 (1995) 875-884.

[43] J.S. Isaacson, B. Walmsley, Amplitude and time course of spontaneous and evoked excitatory postsynaptic currents in bushy cells of the anteroventral cochlear nucleus, J. Neurophysiol. 76 (1996) 1566-1571.

[44] L. Jeffress, A place theory of sound localization, J. Comp. Physiol. Psychol. 41 (1948) 35-39.

[45] S. Jhaveri, K. Morest, Sequential alterations of neuronal architecture in nucleus magnocellularis of the developing chicken: a Golgi study, Neuroscience 7 (1982) 837-853.

[46] P.X. Joris, L.H. Carney, P.H. Smith, T.C. Yin, Enhancement of neural synchronization in the anteroventral cochlear nucleus. I. Responses to tones at the characteristic frequency, J. Neurophysiol. 71 (1994) 1022-1036.

[47] P.X. Joris, P.H. Smith, T.C. Yin, Coincidence detection in the auditory system: 50 years after Jeffress, Neuron 21 (1998) 12351238 .

[48] A.W. Joseph, R.L. Hyson, Coincidence detection by binaural neurons in the chick brain stem, J. Neurophysiol. 69 (4) (1993) 1197-1211.

[49] G. Klump, Sound localization in birds, in: R.J. Dooling, R.R. Fay, A.N. Popper (Eds.), Comparative Hearing: Birds and Reptiles, Springer-Verlag, 2000. 
[50] G.M. Klump, E. Curio, W. Windt, The great tits (Parus-Major) auditory resolution in azimuth, J. Comp. Physiol. A 158 (1986) 383-390.

[51] E. Knudsen, M. Konishi, Mechanisms of sound localization in the barn owl (Tyto alba), J. Comp. Physiol. 133 (1979) 13-21.

[52] E.I. Knudsen, G.G. Blasdel, M. Konishi, Sound localization by the barn owl (Tyto alba) measured with the search coil technique, J. Comp. Physiol. 133 (1979) 1-11.

[53] M. Konishi, Deciphering the brain's codes, Neural Comput. 3 (1991) 1-18.

[54] M. Konishi, Study of sound localization by owls and its relevance to humans, Comp. Biochem. Physiol. A 126 (2000) 459-469.

[55] C. Köppl, Auditory nerve terminals in the cochlear nucleus magnocellularis: differences between low and high frequencies, J. Comp. Neurol. 339 (1994) 438-446.

[56] C. Köppl, Frequency tuning and spontaneous activity in the auditory nerve and cochlear nucleus magnocellularis of the barn owl Tyto alba, J. Neurophysiol. 77 (1997) 364-377.

[57] C. Köppl, Phase locking to high frequencies in the auditory nerve and cochlear nucleus magnocellularis of the barn owl, Tyto alba, J. Neurosci. 17 (1997) 3312-3321.

[58] C. Köppl, C.E. Carr, Low-frequency pathway in the barn owl's auditory brainstem, J. Comp. Neurol. 378 (1997) 265-282.

[59] C. Köppl, C.E. Carr, Computational diversity in the cochlear nucleus angularis of the barn owl, J. Neurophysiol. 89 (2003) 2313-2329.

[60] C. Köppl, O. Gleich, G.A. Manley, An auditory fovea in the barn owl cochlea, J. Comp. Physiol. A 171 (1993) 695-704.

[61] C. Köppl, G. Yates, Coding of sound pressure level in the barn owl's auditory nerve, J. Neurosci. 19 (1999) 9674-9686.

[62] M.F. Kubke, C.E. Carr, Development of the auditory brainstem of birds: comparison between barn owls and chickens, Hearing Res. 147 (2000) 1-20.

[63] M.F. Kubke, D.P. Massoglia, C.E. Carr, Developmental changes underlying the formation of the specialized time coding circuits in barn owls (Tyto alba), J. Neurosci. 22 (2002) 7671-7679.

[64] S. Kuwada, T. Yin, R. Wickesburg, Response of cat inferior colliculus neurons to binaural beat stimuli: possible mechanisms for sound localization, Science 206 (1979) 586-588.

[65] C.M. Macica, C.A. von Hehn, L.Y. Wang, C.S. Ho, S. Yokoyama, R.H. Joho, L.K. Kaczmarek, Modulation of the $\mathrm{kv} 3.1 \mathrm{~b}$ potassium channel isoform adjusts the fidelity of the firing pattern of auditory neurons, J. Neurosci. 23 (2003) 1133-1141.

[66] Z.F. Mainen, T.J. Sejnowski, Reliability of spike timing in neocortical neurons, Science 268 (1995) 1503-1506.

[67] P.B. Manis, Membrane properties and discharge characteristics of guinea pig dorsal cochlear nucleus neurons studied in vitro, J. Neurosci. 10 (1990) 2338-2351.

[68] P.B. Manis, S.O. Marx, Outward currents in isolated ventral cochlear nucleus neurons, J. Neurosci. 11 (1991) 2865-2880.

[69] G.A. Manley, Cochlear mechanisms from a phylogenetic viewpoint, Proc. Natl. Acad. Sci. USA 97 (2000) 11736-11743.

[70] G.A. Manley, C. Köppl, Phylogenetic development of the cochlea and its innervation, Curr. Opin. Neurobiol. 8 (1998) 468-474.

[71] D. McAlpine, D. Jiang, A.R. Palmer, A neural code for lowfrequency sound localization in mammals, Nat. Neurosci. 4 (2001) 396-401.

[72] A. Moiseff, Bicoordinate sound localization by the barn owl, J. Comp. Physiol. 164 (1989) 637-644.

[73] A. Moiseff, M. Konishi, Neuronal and behavioral sensitivity to binaural time differences in the owl, J. Neurosci. 1 (1981) 4048.

[74] P. Monsivais, L. Yang, E.W. Rubel, GABAergic inhibition in nucleus magnocellularis: implications for phase locking in the avian auditory brainstem, J. Neurosci. 20 (2000) 2954 2963.
[75] M.J. Nicol, B. Walmsley, Ultrastructural basis of synaptic transmission between endbulbs of Held and bushy cells in the rat cochlear nucleus, J. Physiol. 539 (2002) 713-723.

[76] D. Oertel, Synaptic responses and electrical properties of cells in brain slices of the mouse anteroventral cochlear nucleus, J. Neurosci. 3 (1983) 2043-2053.

[77] D. Oertel, The role of intrinsic neuronal properties in the encoding of auditory information in the cochlear nuclei, Curr. Opin. Neurobiol. 1 (1991) 221-228.

[78] D. Oertel, Encoding of timing in the brain stem auditory nuclei of vertebrates, Neuron 19 (1997) 959-962.

[79] D. Oertel, The role of timing in the brain stem auditory nuclei of vertebrates, Annu. Rev. Physiol. 61 (1999) 497-519.

[80] D. Oertel, R. Bal, S.M. Gardner, P.H. Smith, P.X. Joris, Detection of synchrony in the activity of auditory nerve fibers by octopus cells of the mammalian cochlear nucleus, Proc. Natl. Acad. Sci. USA 97 (2000) 11773-11779.

[81] D. Oertel, S.H. Wu, Morphology and physiology of cells in slice preparations of the dorsal cochlear nucleus of mice, J. Comp. Neurol. 283 (1989) 228-247.

[82] E.M. Overholt, E.W. Rubel, R.L. Hyson, A circuit for coding interaural time differences in the chick brainstem, J. Neurosci. 12 (1992) 1698-1708.

[83] A.G. Paolini, J.V. FitzGerald, A.N. Burkitt, G.M. Clark, Temporal processing from the auditory nerve to the medial nucleus of the trapezoid body in the rat, Hearing Res. 159 (2001) 101-116.

[84] T.N. Parks, E.W. Rubel, Organization and development of brain stem auditory nuclei of the chicken: organization of projections from n. magnocellularis to n. laminaris, J. Comp. Neurol. 164 (1975) 435-448.

[85] J.L. Pena, M. Konishi, Cellular mechanisms for resolving phase ambiguity in the owl's inferior colliculus, Proc. Natl. Acad. Sci. USA 97 (2000) 11787-11792.

[86] J.L. Pena, S. Viete, Y. Albeck, M. Konishi, Tolerance to sound intensity of binaural coincidence detection in the nucleus laminaris of the owl, J. Neurosci. 16 (1996) 7046-7054.

[87] J.L. Pena, S. Viete, K. Funabiki, K. Saberi, M. Konishi, Cochlear and neural delays for coincidence detection in owls, J. Neurosci. 21 (2001) 9455-9459.

[88] I.M. Raman, L.O. Trussell, The kinetics of the response to glutamate and kainate in neurons of the avian cochlear nucleus, Neuron 9 (1992) 173-186.

[89] S. Ramon y Cajal, Les ganlions terminaux du nerf acoustique des oiseaux, Trab. Inst. Cajal Invest. Biol. 6 (1908) 195225.

[90] M. Rathouz, L. Trussell, Characterization of outward currents in neurons of the avian nucleus magnocellularis, J. Neurophysiol. 80 (1998) 2824-2835.

[91] A.D. Reyes, E.W. Rubel, W.J. Spain, Membrane properties underlying the firing of neurons in the avian cochlear nucleus, J. Neurosci. 14 (1994) 5352-5364.

[92] A.D. Reyes, E.W. Rubel, W.J. Spain, In vitro analysis of optimal stimuli for phase-locking and time-delayed modulation of firing in avian nucleus laminaris neurons, J. Neurosci. 16 (1996) 9931007.

[93] W.S. Rhode, P.H. Smith, Physiological studies on neurons in the dorsal cochlear nucleus of cat, J. Neurophysiol. 56 (1986) 287 307.

[94] W.S. Rhode, P.H. Smith, D. Oertel, Physiological response properties of cells labeled intracellularly with horseradish peroxidase in cat dorsal cochlear nucleus, J. Comp. Neurol. 213 (1983) 426-447.

[95] J.S. Rothman, E.D. Young, P.B. Manis, Convergence of auditory nerve fibers onto bushy cells in the ventral cochlear nucleus: implications of a computational model, J. Neurophysiol. 70 (1993) 2562-2583. 
[96] E.W. Rubel, T.N. Parks, Organization and development of the avian brainstem auditory system, in: G.M. Edelman, W.E. Gall, W.M. Cowan (Eds.), Auditory Function: Neurobiological Bases of Hearing, John Wiley, New York, 1988, pp. 3-92.

[97] D.K. Ryugo, The auditory nerve: peripheral innervation, cell body morphology, and central projections, in: D.B. Webster, A.N. Popper, R.R. Fay (Eds.), The Mammalian Auditory Pathway: Neuroanatomy, Springer-Verlag, New York, 1992, pp. 23-65.

[98] D.K. Ryugo, S. Sento, Synaptic connections of the auditory nerve in cats: relationship between endbulbs of held and spherical bushy cells, J. Comp. Neurol. 305 (1991) 35-48.

[99] B.L. Sabatini, W.G. Regehr, Timing of synaptic transmission, Annu. Rev. Physiol. 61 (1999) 521-542.

[100] K. Saberii, Y. Takahashi, R. Egnor, H. Farahbod, J. Mazer, M. Konishi, Detection of large interaural delays and its implication for models of binaural interaction, J. Assoc. Res. Otolaryngol. 3 (2002) 80-88.

[101] S. Sento, D.K. Ryugo, Endbulbs of Held and spherical bushy cells in cats: morphological correlates with physiological properties, J. Comp. Neurol. 280 (1989) 553-562.

[102] T.M. Shackleton, B.C. Skottun, R.H. Arnott, A.R. Palmer, Interaural time difference discrimination thresholds for single neurons in the inferior colliculus of Guinea pigs, J. Neurosci. 23 (2003) 716-724.

[103] S.A. Shamma, N.M. Shen, P. Gopalaswamy, Stereausis: binaural processing without neural delays, J. Acoust. Soc. Am. 86 (1989) 989-1006.

[104] J.Z. Simon, C.E. Carr, S.A. Shamma, A dendritic model of coincidence detection in the avian brainstem, Neurocomputing 26-27 (1999) 263-269.

[105] B.C. Skottun, T.M. Shackleton, R.H. Arnott, A.R. Palmer, The ability of inferior colliculus neurons to signal differences in interaural delay, Proc. Natl. Acad. Sci. USA 98 (2001) 1405014054.

[106] P.H. Smith, Structural and functional differences distinguish principal from nonprincipal cells in the Guinea pig MSO slice, J. Neurophysiol. 73 (4) (1995) 1653-1667.

[107] P.H. Smith, P.X. Joris, T.C. Yin, Projections of physiologically characterized spherical bushy cell axons from the cochlear nucleus of the cat: evidence for delay lines to the medial superior olive, J. Comp. Neurol. 331 (1993) 245-260.

[108] P.H. Smith, P.X. Joris, T.C.T. Yin, Axonal delay lines for computation of interaural time delays (1992).

[109] D. Soares, J.Z. Simon, J. Smolders, C.E. Carr, Interaural time difference coding in the brainstem of the American alligator (2004).

[110] W.E. Sullivan, M. Konishi, Segregation of stimulus phase and intensity coding in the cochlear nucleus of the barn owl, J. Neurosci. 4 (1984) 1787-1799.

[111] W.E. Sullivan, M. Konishi, Neural map of interaural phase difference in the owl's brainstem, Proc. Natl. Acad. Sci. USA 83 (1986) 8400-8404.

[112] M.R. Szpir, S. Sento, D.K. Ryugo, Central projections of cochlear nerve fibers in the alligator lizard, J. Comp. Neurol. 295 (1990) 530-547.

[113] T. Takahashi, A. Moiseff, M. Konishi, Time and intensity cues are processed independently in the auditory system of the owl, J. Neurosci. 4 (1984) 1781-1786.

[114] T.T. Takahashi, M. Konishi, Projections of the cochlear nuclei and nucleus laminaris to the inferior colliculus of the barn owl, J. Comp. Neurol. 274 (1988) 190-211.
[115] D.J. Tollin, The lateral superior olive: a functional role in sound source localization, Neuroscientist 9 (2003) 127-143.

[116] L.O. Trussell, Cellular mechanisms for preservation of timing in central auditory pathways, Curr. Opin. Neurobiol. 7 (1997) $487-$ 492.

[117] L.O. Trussell, Synaptic mechanisms for coding timing in auditory neurons, Annu. Rev. Physiol. 61 (1999) 477-496.

[118] H. Wagner, J.A. Mazer, M. von Campenhausen, Response properties of neurons in the core of the central nucleus of the inferior colliculus of the barn owl, Eur. J. Neurosci. 15 (2002) 1343-1352.

[119] H. Wagner, T. Takahashi, M. Konishi, Representation of interaural time difference in the central nucleus of the barn owl's inferior colliculus, J. Neurosci. 7 (1987) 3105-3116.

[120] L.Y. Wang, L. Gan, I.D. Forsythe, L.K. Kaczmarek, Contribution of the Kv3.1 potassium channel to high-frequency firing in mouse auditory neurones, J. Physiol. 509 (Pt 1) (1998) 183194.

[121] L.Y. Wang, L.K. Kaczmarek, High-frequency firing helps replenish the readily releasable pool of synaptic vesicles, Nature 394 (1998) 384-388.

[122] W. Wilczynski, Central neural systems subserving a homoplasous periphery, Am. Zool. 24 (1984) 755-763.

[123] S.H. Wu, D. Oertel, Intracellular injection with horseradish peroxidase of physiologically characterized stellate and bushy cells in slices of mouse anteroventral cochlear nucleus, J. Neurosci. 4 (1984) 1577-1588.

[124] S.H. Wu, Physiological properties of neurons in the ventral nucleus of the lateral lemniscus of the rat: intrinsic membrane properties and synaptic responses, J. Neurophysiol. 81 (1999) 2862-2874.

[125] S.H. Wu, J.B. Kelly, In vitro brain slice studies of the rat's dorsal nucleus of the lateral lemniscus. II. Physiological properties of biocytin-labeled neurons, J. Neurophysiol. 73 (2) (1995) 794 809.

[126] L. Yang, P. Monsivais, E.W. Rubel, The superior olivary nucleus and its influence on nucleus laminaris: a source of inhibitory feedback for coincidence detection in the avian auditory brainstem, J. Neurosci. 19 (1999) 2313-2325.

[127] T.C. Yin, L.H. Carney, P.X. Joris, Interaural time sensitivity in the inferior colliculus of the albino cat, J. Comp. Neurol. 295 (1990) 438-448.

[128] T.C. Yin, J.C. Chan, Interaural time sensitivity in medial superior olive of cat, J. Neurophysiol. 64 (1990) 465-488.

[129] T.C. Yin, J.C. Chan, L.H. Carney, Effects of interaural time delays of noise stimuli on low-frequency cells in the cat's inferior colliculus. III. Evidence for cross-correlation, J. Neurophysiol. 58 (1987) 562-583.

[130] S.R. Young, E.W. Rubel, Frequency-specific projections of individual neurons in chick brainstem auditory nuclei, J. Neurosci. 7 (1983) 1373-1378.

[131] S.R. Young, E.W. Rubel, Embryogenesis of arborization pattern and topography of individual axons in N. Laminaris of the chicken brain stem, J. Comp. Neurol. 254 (1986) 425 459.

[132] S. Zhang, L.O. Trussell, A characterization of excitatory postsynaptic potentials in the avian nucleus magnocellularis, J. Neurophysiol. 72 (1994) 705-718.

[133] S. Zhang, L.O. Trussell, Voltage clamp analysis of excitatory synaptic transmission in the avian nucleus magnocellularis, J. Physiol. (Lond.) (1994). 